\title{
The distribution of plasma phenytoin levels in epileptic patients
}

\author{
P. T. LASCELlES, R. S. KOCEN, AND E. H. REYNOLDS \\ From the Department of Chemical Pathology, the Institute of Neurology and National Hospitals for Nervous \\ Diseases, Queen Square and Maida Vale, London
}

SUMMARY Plasma phenytoin levels were estimated in 111 adult epileptic patients. A wide scatter of values was found, with over half outside the therapeutic limits of 10 to $20 \mu \mathrm{g} / \mathrm{ml}$. Phenytoin tolerance tests carried out in five patients revealed a possible failure to metabolize the drug adequately in three of them. Factors affecting the plasma phenytoin level are discussed. The importance of this assay is seen in view of the number of patients potentially at risk from toxic blood levels in the absence of accepted clinical manifestations of acute or subacute intoxication.

Phenytoin (diphenylhydantoin) has been used successfully in the treatment of epilepsy since its introduction by Merritt and Putnam in 1938. Although the optimal therapeutic effect is achieved close to the toxic range (Merritt and Putnam, 1938; Roseman, 1961), the majority of patients have been managed in the past without prescribing phenytoin on a weight basis or by reference to its assay in the blood, especially as the clinical manifestations of acute intoxication are easily recognized in most patients.

However, a few studies have already indicated a very wide scatter of serum phenytoin levels in patients on the same dose of the drug (Buchthal, Svensmark, and Schiller, 1960; Triedman, Fishman, and Yahr, 1960; Loeser, 1961; Husby, 1963; Stensrud and Palmer, 1964; Gibberd, Dunne, Handley, and Hazleman, 1970). In addition, there are some clinical and experimental observations that raise the suspicion that chronic intoxication may develop insidiously in patients on long-term therapy (see Reynolds, 1970). Even the recognition of acute or subacute intoxication can be difficult in a few patients with chronic neurological deficits (Frantzen, Hansen, Hansen, and Kristensen, 1967; Reynolds, Kocen, and Lascelles, 1970). Furthermore, the factors which influence phenytoin levels-for example, genetic, other drugs, etc.-are incompletely understood (Kutt and McDowell, 1968).

For these reasons it seemed desirable to study the blood levels of a series of epileptic patients attending a neurological hospital.

\section{METHODS}

PATIENTS One hundred and eleven adult epileptics of both sexes attending the National Hospitals for Nervous Diseases were selected on the basis of a long history of continuous anticonvulsant treatment for several years, and in a small number of present or past episodes of drug intoxication as evidenced by nystagmus, dysarthria, ataxia, or gum hypertrophy. All except 12 were on phenytoin $300 \mathrm{mg}$ daily in divided doses. Of these 12,10 were on $400 \mathrm{mg}$ daily in divided doses and two were on larger doses. All patients were on other drugs, usually phenobarbitone but occasionally primidone, mesantoin, sulthiame, phenylethylacetylurea, folic acid, or psychotropic drugs. None showed clinical or biochemical evidence or renal, liver, or gastrointestinal disorders.

PHENYTOIN ASSAY Plasma phenytoin was measured by the method of Wallace, Biggs, and Dahl (1965). This was found to be satisfactory giving a high recovery of added phenytoin $(91 \%)$ and highly reproducible results (coefficient of variation $5 \%$ ) with near linear calibration curves. Its advantages over previous methods are that it is highly specific, not being interfered with by other drugs (particularly phenobarbitone), and the method is accepted as being specific for forensic purposes (Wallace et al., 1965).

The final estimation of the brominated derivative of phenytoin was measured in water by scanning with an SP 800 between $220 \mathrm{~m} \mu$ and $320 \mathrm{~m} \mu$ with a maximal extinction at $257 \mathrm{~m} \mu$.

PHeNYTOIN TOLERANCE TESTS Phenytoin $300 \mathrm{mg}$ daily in divided doses was given to patients who had been without the drug for at least 10 days. They were, however, 
receiving phenobarbitone during the test, as it was not possible for ethical reasons to discontinue all anticonvulsant therapy. Previous treatment had consisted of phenobarbitone and phenytoin in all patients and primidone in addition in two. Blood levels were assayed at intervals for two weeks.

\section{RESULTS}

Plasma phenytoin was assayed on 111 patients over a period of 19 months. The results are shown in Fig. 1.

The two patients on a dose greater than $400 \mathrm{mg}$ daily had high blood levels-that is, $34 \mu \mathrm{g} / \mathrm{ml}$. and $43 \mu \mathrm{g} / \mathrm{ml}$. The ten patients on $400 \mathrm{mg}$ daily showed a wide scatter of blood levels, two of these being $25 \mu \mathrm{g} / \mathrm{ml}$. and $32 \mu \mathrm{g} / \mathrm{ml}$, while the other eight were $24 \mu \mathrm{g} / \mathrm{ml}$. or less.

The results of the phenytoin tolerance tests are shown graphically in Fig. 2.

The two patients with normal response were selected from the 'middle' portion of the distribution curve (original plasma phenytoin levels being $14 \mu \mathrm{g} / \mathrm{ml}$. and $20 \mu \mathrm{g} / \mathrm{ml}$.), while two of the patients with the abnormal response were taken from the 'right-hand' portion of the distribution (original plasma phenytoin levels being $35 \mu \mathrm{g} / \mathrm{ml}$. and 50 $\mu \mathrm{g} / \mathrm{ml}$.; the third patient was added later). After 14 days the normal patients were in 'steady state' of plasma concentration, while the other three patients continued to show a rise in blood levels during this period to greater than $32 \mu \mathrm{g} / \mathrm{ml}$.

\section{DISCUSSION}

Phenytoin is absorbed slowly but fairly completely from the gut, a divided daily dose of $5 \mathrm{mg} / \mathrm{kg}$ body weight taking up to 15 days to achieve a blood plateau (Buchthal et al., 1960; Loeser, 1961). It is detoxicated in the liver by the microsomal P450 hydroxylation system to 5-phenyl-5-parahydroxyphenylhydantoin (HPPH) which is then conjugated and excreted in the urine. Normally less than $5 \%$ of the undetoxicated drug is excreted (Butler. 1957), and the biological half-life is 26 hours (Solomon and Schrogie, 1967). It is the undetoxicated compound which is therapeutically active and which is measured (both free and combined with protein) in the blood.

Our results confirm the observations of Triedman et al. (1960); Loeser (1961), Husby (1963), and Stensrud and Palmer (1964), that patients on a standard dose of phenytoin have a wide scalter of serum levels (Fig. 1). According to Buchthal et al. (1960), the therapeutic range is 10 to $20 \mu \mathrm{g} / \mathrm{ml}$

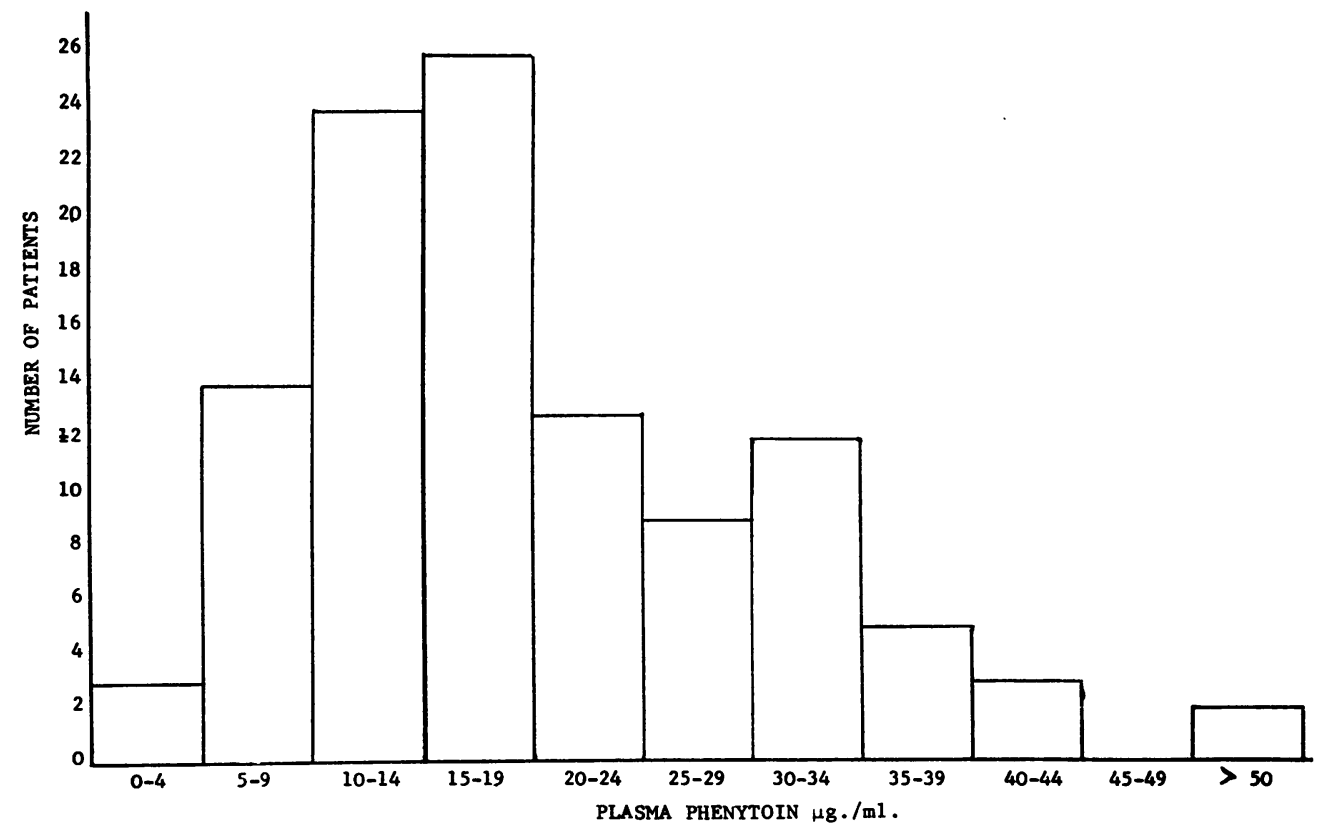

FIG. 1. Frequency distribution histogram of plasma phenytoin levels in 111 patients. 


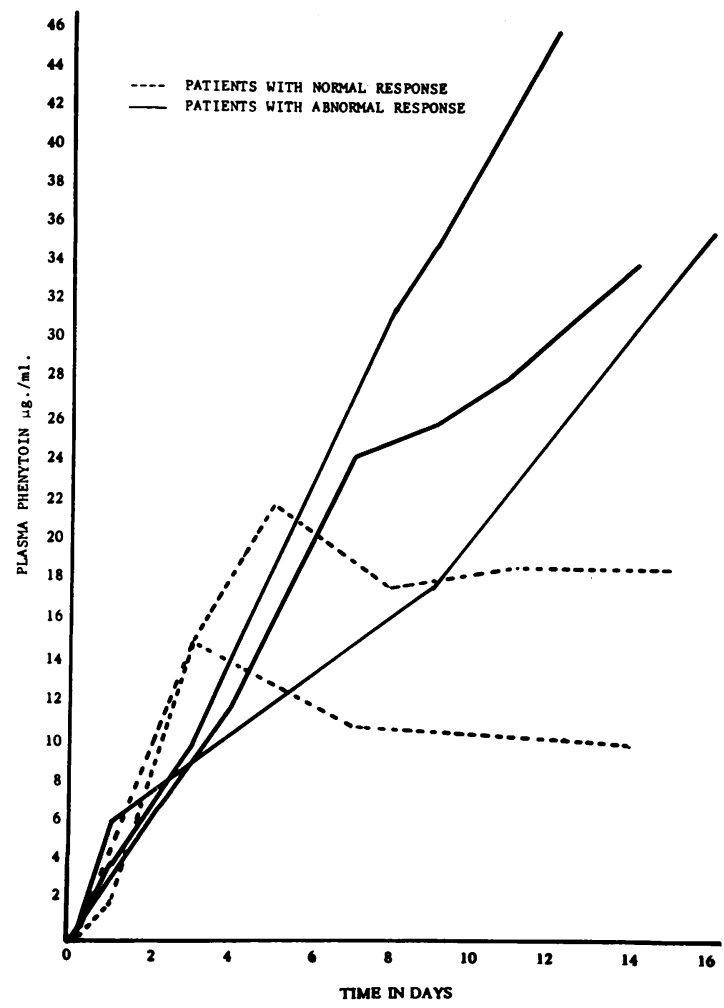

FIG. 2. Phenytoin tolerance tests.

Although the mean and mode of the distribution of our figures lay within this range, as many as $55 \%$ of our patients were outside these limits. Nineteen per cent were below $10 \mu \mathrm{g} / \mathrm{ml}$. and $36 \%$ were above $20 \mu \mathrm{g} / \mathrm{ml}$. Moreover, the distribution is clearly not normal but is skew at the higher levels. The figures are not sufficiently large to allow definite conclusions to be drawn as to the exact form of the distribution as to whether it is, for example, log normal or whether there is a second peak.

Several possibilities must be considered as the cause of high levels.

1 . The dose of phenytoin per se, or dose in relation to weight could be responsible for the higher levels; but as our 12 patients on higher doses were also widely scattered on the distribution curve, and as there was no difference in weight between those with high and low levels, this is unlikely to be the explanation, as noted in previous reports.

2. As judged by clinical criteria and routine laboratory tests, there were no grounds for suspecting liver or renal disease.

3. Selection of patients is a possible explanation for any unusual distribution of results, but for reasons to be discussed below in relation to the tolerance tests, if selection has affected our results it is unlikely to be the only factor.

4. Many drugs are known to affect the rate of detoxication of phenytoin. These include phenobarbitone (Cucinell, Koster, Conney, and Burns, 1963); sulthiame (Hansen, Kristensen, and Skovsted, 1968), para-aminosalicylic acid and isoniazid (Kutt, Winters, and McDowell, 1966a), dicoumarol (Hansen, Kristensen, Skovsted, and Christensen, 1966), disulfiram (Olesen, 1967), and phenyramidol (Solomon and Schrogie, 1967). As phenobarbitone usually stimulates phenytoin metabolism (Kutt, Haynes, Verebely, and McDowell, 1969), only sulthiame may possibly be incriminated in elevating the drug level in a few of our patients. However, those of our patients on sulthiame were also widely scattered on the phenytoin level distribution curve.

5. Genetically determined variation in the ability to detoxicate phenytoin remains as an important possibility. Genetic polymorphism is now wellestablished for many other drugs (Evans, 1963), and may manifest itself in various ways.

Kutt, Wolk, Scherman, and McDowell (1964a) have described one family in which two out of four siblings and their mother were unable to metabolize phenytoin adequately in a standard dose of $4 \mathrm{mg} / \mathrm{kg}$ though lower doses could be handled normally. They showed that these subjects had an abnormally low excretion of HPPH, and that the defect was inherited as an autosomal recessive. They speculated that the condition may be more common in less severe forms and that there may exist a 'spectrum of ceilings' with regard to the maximal ability of the P450 hydroxylation system to deal with a phenytoin level. Clearly such a state of affairs is quite different from that described by Evans (1963) in relation to isonicotinic acid, in which normal subjects are more clearly divided into rapid and slow acetylators.

The matter is further complicated by the possibility that a genetic defect of drug metabolism may express itself as a variation in the inducibility of detoxication by other drugs. Thus such a mechanism would not be detected in the majority of patients without administering to them several drugs together in different combinations, and clearly there would be ethical problems involved in such a study.

The results of the tolerance tests (Fig. 2) are consistent with the concept of genetic variation in the ability to metabolize the drug. The two patients selected from the middle range of the curve (Fig. 1) rapidly reached a steady state with normal or near normal levels, while three patients from the upper end of the curve rapidly built up high levels without reaching equilibrium within 10 days. The fact that 
these three had high levels originally suggests that increased self-inducibility by phenytoin would not have resulted in a subsequent fall in blood levels during a more prolonged test.

Estimations of urine HPPH have not been carried out on these patients so far for purely methodological reasons. These and family studies on a large scale will be required to prove the genetic basis of the mechanism.

Genetic factors may also contribute to the very low phenytoin levels in some patients, due to excessively rapid metabolism of the drug (Kutt, Haynes, and McDowell, 1966b). However, other possible factors are the stimulation of phenytoin metabolism by phenobarbitone (Cucinell et al., 1963), malabsorption of the drug (Kutt et al., 1966b) and failure to take the prescribed dose of the drug (Schiller and Buchthal, 1958; Lund, Jørgensen, and Kühl, 1964; Kutt et al., 1966b; Gibberd et al., 1970).

Our own and previous findings have implications for the management of epileptic patients both in relation to the control of attacks and the prevention of toxic effects.

As only $45 \%$ of our patients had blood levels in the therapeutic range, it is apparent that some patients are not receiving enough of the drug and others are having too much. As most of our patients were on the same dose, it is clear that more efficient therapeutic use of the drug would be obtained by monitoring blood levels. Improvement in fit control can be obtained not only by increasing the dose in those with low levels but probably also in some patients by reducing the dose in those with abnormally high levels. It is not widely appreciated that toxic doses of phenytoin may aggravate epilepsy and even precipitate status epilepticus (Levy and Fenichel, 1965). Eighteen of our patients with blood levels initially above $25 \mu \mathrm{g} / \mathrm{ml}$. in whom the dose of the drug was reduced, at follow-up at six months or more, showed a reduction in fit frequency by at least $50 \%$; in six there was no change in attack frequency; and in only two was there an increase in fits requiring the addition of further therapy.

Kutt, Winters, Kokenge, and McDowell (1964b) and Haerer and Grace (1969) have reported a close correlation between toxic symptoms and signs (especially nystagmus) and blood drug levels. This has not been our experience especially in relation to the more insidiously developing toxic effects. Indeed, we have observed a few patients with severe toxicity (ataxia and drowsiness) and no nystagmus. Furthermore, some patients seem unduly sensitive to even relatively low (therapeutic) levels of the drug, possibly because of underlying brain damage.
There would seem, therefore, to be a case for $\bar{z}$ more frequent monitoring of phenytoin therapy both for the control of fits and the prevention of toxicity, especially as our results seem to emphasize the frequency of patients potentially at risk from toxic blood levels. Tolerance tests are not practicable for routine purposes, particularly if continued until full equilibrium has been reached, but individual assays of blood phenytoin levels are a valuable guide in the practical management of epileptic patients.

We wish to record our thanks to Mr. M. Sabur, for his analytical skill, without which this work would not have been possible, and to thank the physicians and surgeons of The National Hospitals for Nervous Diseases for kindly : llowing us to investigate patients under their care.

\section{REFERENCES}

Buchthal, F., Svensmark, O., and Schiller, P. J. (1960). Clinical and electro-encephalographic correlations with serum levels of diphenylhydantoin. Arch. Neuroto (Chic.), 2, 624-630.

Butler, T. C. (1957). The metabolic conversion of 5, diphenylhydantoin to 5 (P-hydroxyphenol)-5-pheny? hydantoin. J. Pharmacol. exp. Ther., 119, 1-11.

Cucinell, S. A., Koster, R., Conney, A. H., and Burns, J. $\delta$ (1963). Stimulatory effect of phenobarbital on metabo ism of diphenylhydantoin. J. Pharmacol. exp. Ther., 14h్ $157-160$

Evans, D. A. P. (1963). Pharmacogenetics. Amer. J. Med., 34 639-662.

Frantzen, E., Hansen, J. M., Hansen, O. E., and Kristensen, M. (1967). Phenytoin (dilantin) intoxication. Acta neurol. scand., 43, 440-446.

Gibberd, F. B., Dunne, J. F., Handley, A. J., and Hazleman, B. L. (1970). Supervision of epileptic patients taking phenytoin. Brit. med. J., 1, 147-149.

Hansen, J. M., Kristensen, M., and Skovsted, L. (1968). Sulthiame (ospolot) as inhibitor of diphenylhydantoin metabolism. Epilepsia (Amst.), 9, 17-22.

Hansen, J. M., Kristensen, M., Skovsted, L., and Christensen, L. K. (1966). Dicoumarol-induced diphenylhydantoin intoxication. Lancet, 2, 265-266.

Haerer, A. F., and Grace, J. B. (1969). Studies of anticonvulsant levels in epileptics. Acta neurol. scand., 45, 18-31.

Husby, J. (1963). Delayed toxicity and serum concentrations of phenytoin. Dan. med. Bul., 10, 236-239.

Kutt, H., Haynes, J., and McDowell, F. (1966b). Some causes of ineffectiveness of diphenylhydantoin, Arch. Neurol. (Chic.), 14, 489-492.

Kutt, H., Haynes, J., Verebely, K., and McDowell, F. (1969). The effect of phenobarbital on plasma diphenylhydantoin level and metabolism in man and in rat liver microsomes. Neurology (Minneap.), 19, 611-616.

Kutt, H., and McDowell, F. (1968). Management of epilepsy with diphenylhydantoin sodium. Dosage regulation for problem patients. J. Amer. med. Ass., 203, 969-972.

Kutt, H., Winters, W., Kokenge, R., and McDowell, F. (1964b). Diphenylhydantoin metabolism, blood levels, and toxicity. Arch. Neurol. (Chic.), 11, 642-648.

Kutt, H., Winters, W., and McDowell, F. (1966a). Depres- 
sion of parahydroxylation of diphenylhydantoin by antituberculosis chemotherapy. Neurology (Minneap.), 16, 594-602.

Kutt, H., Wolk, M., Scherman, R., and McDowell, F. (1964a). Insufficient parahydroxylation as a cause of diphenylhydantoin toxicity. Neurology (Minneap.), 14, 542-548.

Levy, L. L., and Fenichel, G. M. (1965). Diphenylhydantoin activated seizures. Neurology (Minneap.), 15, 716-722.

Loeser, E. W. (1961). Studies on the metabolism of diphenylhydantoin (dilantin). Neurology (Minneap.), 11, 424-429.

Lund, M., Jørgensen, R. S., and Kühl, V. (1964). Serum diphenylhydantoin (phenytoin) in ambulant patients with epilepsy. Epilepsia (Amst.), 5, 51-58.

Merritt, H. H., and Putnam, T. J. (1938). Sodium diphenylhydantoinate in the treatment of convulsive disorders. J. Amer. med. Ass., 111, 1068-1073.

Olesen, O. V. (1967). Influence of disulfiram and calcium carbimide on the serum diphenylhydantoin. Arch. Neurol. (Chic.), 16, 642-644.

Reynolds, E. H. (1970). Iatrogenic disorders in epilepsy. In Modern Trends in Neurology, Series 5. Edited by Denis Williams. Butterworth: London.
Reynolds, E. H., Kocen, R. S., and Lascelles, P. T. (1970). Cerebellar atrophy in epileptic patients. (To be published.)

Roseman, E. (1961). Dilantin toxicity: a clinical and electroencephalographic study. Neurology (Minneap.), 11, 912-921.

Schiller, P. J., and Buchthal, F. (1958). Diphenylhydantoin and phenobarbital in serum in patients with epilepsy. Dan. med. Bull., 5, 161-163.

Solomon, H. M., and Schrogie, J. J. (1967). Effect of phenyramidol on the metabolism of diphenylhydantoin. Clin. Pharmacol. Ther., 8, 554-556.

Stensrud, P. A., and Palmer, H. (1964). Serum phenytoin determinations in epileptics. Epilepsia (Amst.), 5, 364-370.

Triedman, H. M., Fishman, R. A., and Yahr, M. D. (1960). Determination of plasma and cerebrospinal fluid levels of dilantin in the human. Trans. Amer. neurol. Ass., 166-170.

Wallace, J., Biggs, J., and Dahl, E. V. (1965). Determination of diphenylhydantoin by ultraviolet spectrophotometry. Anal. Chem., 37, 410-413. 